\title{
An Assessment on Driving Behaviourism of Goods Vehicle Drivers in Kerala
}

\section{Sanjai.R.J' , Dr. Jayasholan. T J²}

${ }^{1}$ Research Scholar, Ponnaiyah Ramajayam Institute of Science and Technology University, Deemed to be University, Thanjavur, TamilNadu

${ }^{2}$ Professor of Economics, School of Commerce and Management, Ponnaiyah Ramajayam Institute of Science and Technology University, Deemed to be University, Thanjavur, TamilNadu

Article History:Received:11 november 2020; Accepted: 27 December 2020; Published online: 05 April 2021

\begin{abstract}
Road Safety has become a serious issue in this era as the population in terms of both people as well as vehicles has increased to a large extend. The behaviour of drivers is influenced by several factors, which include their socio-economic - demographic factors and vehicle characteristics. Accidents comprising of goods vehicles have been on the surge in Kerala over the years. Even though the numbers of heavy vehicles plying on Kerala roads are less compared to two wheelers and cars, the proportion of crashes involving heavy vehicles is a cause of concern. Fallacious driving behaviourism is generally considered as the leading root of such accidents. The present study intends to investigate the elements involved in the Driver Behaviour Questionnaire (DBQ), then to explore the relationships between the elements of the DBQ and accident involvement. The data were interpreted using percentage analysis. The analysis showed the level of violations, errors, lapses committed by drivers on the basis of driving behaviourism and non -driving behaviourism of the goods vehicle driver.
\end{abstract}

Keywords: Goods Vehicle Accidents, Driving behaviour, Non -driving behavior s.

\section{Introduction}

Road accidents are one of the major challenges for the transportation sector of any country. Every day a large number of people die in road accidents and hence road accident is stated as the primary cause of death in the world. Even though developed countries take effective measures to rectify the problem and to reduce its impacts on economy, the problem is still an unsolved issue in many developing countries like India. As per literatures, fault of drivers constitute $95 \%$ of the accidents. Average incidents of accidental deaths per year and annual rate of accident death for decades reveal increasing accident death in India and continuous annual increase in the rate of accident deaths. Since, heavy vehicle occupies a major portion of the road, which in turn results in congestion and other traffic problems, it is essential to carry out a study on the accident records of heavy vehicles. Goods vehicles like Lorries and trucks play a vital role in the movement of goods in India. As the goods vehicle drivers are constrained with time and responsibilities they bear, these heavy vehicles often met with fatal accidents. As per the accident statistics it is evident that two wheelers and four wheelers together constitute more than $70 \%$ of the road accidents occurring in a year. It was found that the percentage of goods vehicles involved in accidents is even higher than that of two wheelers and four wheelers. It is thereby evident that the accident statistics of goods vehicles is significant as the other two and should be taken into consideration with equal importance.

Goods vehicles contribute a major share of the fatal accidents and serious injuries in Kerala. Of the total accidents in Kerala, two wheelers constitute more than $50 \%$, followed by four wheelers and heavy vehicles. As goods vehicles like lorry and tippers involves in a high percentage of the fatal accidents and serious injuries in Kerala, and they occupies a large portion of the space, it becomes important to study the perceptions of the drivers and their behavioral aspects during driving, which can be marked as the major reason for their involvement in crashes. The year wise comparison of accident percentage for three major classes of vehicles in Kerala is given in Table 1 .

\section{Table 1}

Year wise comparison of Accident Percentage for the Major Classes of vehicles in Kerala

\begin{tabular}{|c|l|c|c|c|}
\hline Year & \multicolumn{1}{|c|}{ Vehicle Class } & $\begin{array}{c}\text { Total Number of } \\
\text { Vehicles }\end{array}$ & $\begin{array}{c}\text { Accidents } \\
\text { Reported }\end{array}$ & $\begin{array}{c}\text { Accident } \\
\text { Percentage }(\%)\end{array}$ \\
\hline $2011-2012$ & $\begin{array}{l}\text { Two Wheelers } \\
\text { (Scooter/Motor Cycles) }\end{array}$ & 4127227 & 17116 & 0.41 \\
\hline & Cars \& Station Wagons & 1476029 & 10106 & 0.68 \\
\hline & $\begin{array}{l}\text { Goods Vehicle } \\
\text { (Four wheeler and above) }\end{array}$ & 322450 & 3392 & 1.05 \\
\hline
\end{tabular}

Corresponding Author : Sanjai.R.J

Research Scholar, Ponnaiyah Ramajayam Institute of Science and Technology University, Deemed to be University, Thanjavur, TamilNadu 


\begin{tabular}{|c|c|c|c|c|}
\hline Year & Vehicle Class & $\begin{array}{c}\text { Total Number of } \\
\text { Vehicles }\end{array}$ & $\begin{array}{l}\text { Accidents } \\
\text { Reported }\end{array}$ & $\begin{array}{c}\text { Accident } \\
\text { Percentage }(\%)\end{array}$ \\
\hline \multirow[t]{3}{*}{$2012-2013$} & $\begin{array}{l}\text { Two Wheelers } \\
\text { (Scooter/Motor Cycles) }\end{array}$ & 5041495 & 17448 & 0.35 \\
\hline & Cars \& Station Wagons & 1561145 & 9735 & 0.62 \\
\hline & $\begin{array}{l}\text { Goods Vehicle } \\
\text { (Four wheeler and above) }\end{array}$ & 354296 & 2830 & 0.80 \\
\hline \multirow[t]{3}{*}{ 2013-2014 } & $\begin{array}{l}\text { Two Wheelers } \\
\text { (Scooter/Motor Cycles) }\end{array}$ & 5288529 & 20293 & 0.38 \\
\hline & Cars \& Station Wagons & 1806304 & 10233 & 0.57 \\
\hline & $\begin{array}{l}\text { Goods Vehicle } \\
\text { (Four wheeler and above) }\end{array}$ & 373218 & 2869 & 0.77 \\
\hline \multirow[t]{3}{*}{ 2014-2015 } & $\begin{array}{l}\text { Two Wheelers } \\
\text { (Scooter/Motor Cycles) }\end{array}$ & 5828816 & 20434 & 0.35 \\
\hline & Cars \& Station Wagons & 1990840 & 10726 & 0.54 \\
\hline & $\begin{array}{l}\text { Goods Vehicle } \\
\text { (Four wheeler and above) }\end{array}$ & 411347 & 2817 & 0.68 \\
\hline \multirow[t]{3}{*}{$2015-2016$} & $\begin{array}{l}\text { Two Wheelers } \\
\text { (Scooter/Motor Cycles) }\end{array}$ & 6472335 & 3538 & 0.36 \\
\hline & Cars \& Station Wagons & 2178232 & 11817 & 0.54 \\
\hline & $\begin{array}{l}\text { Goods Vehicle } \\
\text { (Four wheeler and above) }\end{array}$ & 419813 & 2665 & 0.63 \\
\hline \multirow[t]{3}{*}{ 2016-2017 } & $\begin{array}{l}\text { Two Wheelers } \\
\text { (Scooter/Motor Cycles) }\end{array}$ & 7077103 & 22459 & 0.32 \\
\hline & Cars \& Station Wagons & 2383565 & 11663 & 0.49 \\
\hline & $\begin{array}{l}\text { Goods Vehicle } \\
\text { (Four wheeler and above) }\end{array}$ & 438709 & 2414 & 0.55 \\
\hline \multirow[t]{3}{*}{ 2017-2018 } & $\begin{array}{l}\text { Two Wheelers } \\
\text { (Scooter/Motor Cycles) }\end{array}$ & 7796669 & 24487 & 0.31 \\
\hline & Cars \& Station Wagons & 2628005 & 11682 & 0.44 \\
\hline & $\begin{array}{l}\text { Goods Vehicle } \\
\text { (Four wheeler and above) }\end{array}$ & 452535 & 2501 & 0.55 \\
\hline \multirow[t]{3}{*}{ 2018-2019 } & $\begin{array}{l}\text { Two Wheelers } \\
\text { (Scooter/Motor Cycles) }\end{array}$ & 8620681 & 25972 & 0.30 \\
\hline & Cars \& Station Wagons & 2991042 & 12172 & 0.41 \\
\hline & $\begin{array}{l}\text { Goods Vehicle } \\
\text { (Four wheeler and above) }\end{array}$ & 477027 & 2446 & 0.51 \\
\hline
\end{tabular}

From the aforesaid table statistics it is evident that the goods vehicle comprising of lorries and tippers involves in a high percentage of the accidents and in this regard, it becomes important to study the perceptions of the drivers and their behavioural aspects during driving, which can be marked as the major reason for their involvement in crashes.

\section{Scope \& Objectives of the Study}

Since the primary cause of road accidents is the fault from the drivers, it is necessary to study the behavioral pattern to understand the significant factors of a driver which have high correlation to the crashes. The study focuses on goods vehicles drivers as they have a considerable contribution to many fatal accidents and serious injuries. The behavioral and socio demographic factors of goods drivers which has high influence on the occurrence of accident is analyzed in this study using questionnaire survey in which each driver is asked to fill their personal details as well as certain predetermined questions regarding their driving mannerisms. The scope of the present study is confined to the behaviourism and socio- demographic aspects of goods vehicle drivers within Kerala.

The major objectives of this study are

1. To study the socio - economic and demographic characteristics of goods vehicle drivers.

2. To correlate driving behaviourism and non-driving behaviourism displayed on roads by interpreting the drivers' knowledge, reaction and practice elements. 


\section{Study Approach \& Data Collection}

There are considerable numbers of studies related to the driver behaviourism and its influence leading to road accidents. And among these, a study by Reason et al, 1990 approach is followed extensively where a measurement scale to review the odd behaviourism will be self - reported by the drivers itself. The present study also has attempted to follow the same approach where a DBQ comprises a set of behavioural attributes and each being categorized under violations, errors and lapses with certain elements that are typically suitable only for Kerala driving road conditions. The primary power of such an approach is that the driver's straight participation in the survey and the misinterpretation can be lessen, provided the drivers participate honestly. The database to be generated from the survey includes the demographic particulars, driving and non driving behaviorism connecting violations, errors \& lapses.

Table 2

Basic driver behavioural parameters identified for goods drivers

\begin{tabular}{|l|l|l|l|}
\hline 1 & Overloaded trips & 12 & Overtaking in non-overtaking zones \\
\hline 2 & Overtaking through left side & 13 & Competitive driving \\
\hline 3 & Speed limit violation & 14 & Rash driving \\
\hline 4 & Drunk and drive & 15 & Use of mobile phones when driving \\
\hline 5 & Improper headlights & 16 & Irresponsible driving in hilly areas \\
\hline 6 & Driving in prohibited time zones & 17 & Driving in prohibited areas \\
\hline 7 & Disturbing the front moving vehicles & 18 & Unnecessary use of horns in signals \\
\hline 8 & Negotiating curves without reducing speed & 19 & Negotiating speed regulators without reducing speed \\
\hline 9 & $\begin{array}{l}\text { Failing to estimate the speed of oncoming } \\
\text { vehicles during overtaking }\end{array}$ & 20 & Unintentional increase of speed \\
\hline 10 & $\begin{array}{l}\text { Failing to maintain a safe gap between the front } \\
\text { moving vehicles }\end{array}$ & 21 & Loosing concentration while driving \\
\hline 11 & Driving while feeling sleepy & & \multicolumn{2}{|l}{} \\
\cline { 1 - 2 } & &
\end{tabular}

There are 51 questioning in the survey related to driving and non- driving mode. The needed sampling was selected based on Bill Godden sample size formula for infinite population. Thus, a total of 1,200 goods vehicles data was taken within Kerala State during the survey. Adequate representations were made in the sample to include routes operated in different terrain conditions viz. plain, rolling and hilly regions and also urban, semiurban and rural areas. Also, each class of goods vehicle drivers' viz. container trailers, lorry and tipper drivers, tanker lorry drivers and LCV drivers. The reply to the questioning to the survey was different for every participant drivers but the basic elements of their behavioural change were almost similar. It was relevant to figure out those behaviours for selecting the suitable questions to be included in the questionnaire.

\section{Study Results}

The primary data collected from the field were edited, coded and analyzed systematically through electronic data processing. Inline with the DBQ organized for goods vehicle drivers representing at various regions of Kerala, a database of the behaviourism condition of the goods drivers was also developed. And from the database, it could be figured out that according to what the driving behaviour of the goods drivers shift with respect to their differing socio-demographic environment. Following are the output after the analysis from the collected database.

As part of the data processing it was spotted out that the participant drivers was ranged between 20 \& 70 years. As moving on, it was found that majority of the participant drivers are educated up to $10^{\text {th }}$ grade of school level and only a minute portion are graduates. Again it was noticed that a greater portion of the participant drivers are married and were living with their family. Also, it was noticed that the number of trips and the total distance covered per day jumbled between 0 to 10 numbers and 0 to $500 \mathrm{kms}$ respectively. The details such as driving experience of participant drivers and the number of accidents involved were also spotted during the analysis.

Table 3

Variations of driving and non-driving behavior related to education

\begin{tabular}{|c|c|c|c|c|c|}
\hline \multirow{2}{*}{ Education } & \multicolumn{3}{|c|}{ Driving } & \multicolumn{2}{c|}{ Non Driving } \\
\cline { 2 - 6 } & Violation & Error & Lapse & Error & Lapse \\
\hline$<10^{\text {th }}$ & $39.7 \%$ & $61.1 \%$ & $67.6 \%$ & $90.7 \%$ & $65.2 \%$ \\
\hline $10^{\text {th }}$ to $12^{\text {th }}$ & $43.3 \%$ & $65.0 \%$ & $75.6 \%$ & $79.9 \%$ & $63.8 \%$ \\
\hline
\end{tabular}




\begin{tabular}{|l|l|l|l|l|l|}
$>12^{\text {th }}$ & $33.9 \%$ & $57.1 \%$ & $77.3 \%$ & $89.8 \%$ & $58.2 \%$ \\
\hline
\end{tabular}

Table 4

Variations of driving and non-driving behavior based on marital status

\begin{tabular}{|l|r|l|l|l|l|}
\hline \multirow{2}{*}{ Marital Status } & \multicolumn{3}{|c|}{ Driving } & \multicolumn{2}{c|}{ Non Driving } \\
\cline { 2 - 6 } & Violation & Error & Lapse & Error & Lapse \\
\hline Married & $28.05 \%$ & $30.03 \%$ & $29.66 \%$ & $44.77 \%$ & $41.30 \%$ \\
\hline Unmarried & $27.92 \%$ & $28.44 \%$ & $32.55 \%$ & $49.46 \%$ & $40.28 \%$ \\
\hline
\end{tabular}

Table 5

Variations of driving and non-driving behavior based on trips per day

\begin{tabular}{|c|c|c|c|c|c|}
\hline \multirow{2}{*}{ Trip Nos. } & \multicolumn{3}{|c|}{ Driving } & \multicolumn{2}{c|}{ Non Driving } \\
\cline { 2 - 6 } & Violation & Error & Lapse & Error & Lapse \\
\hline 0 to 4 & $44.3 \%$ & $68.4 \%$ & $72.8 \%$ & $79.2 \%$ & $66.5 \%$ \\
\hline 4 to 8 & $32.8 \%$ & $55.7 \%$ & $79.1 \%$ & $81.1 \%$ & $58.8 \%$ \\
\hline 8 to 12 & $41.6 \%$ & $60.8 \%$ & $68.8 \%$ & $82.4 \%$ & $61.6 \%$ \\
\hline 12 to 16 & $47.0 \%$ & $68.9 \%$ & $72.7 \%$ & $83.0 \%$ & $65.0 \%$ \\
\hline 16 to 20 & $40.4 \%$ & $65.3 \%$ & $100.0 \%$ & $81.3 \%$ & $47.5 \%$ \\
\hline
\end{tabular}

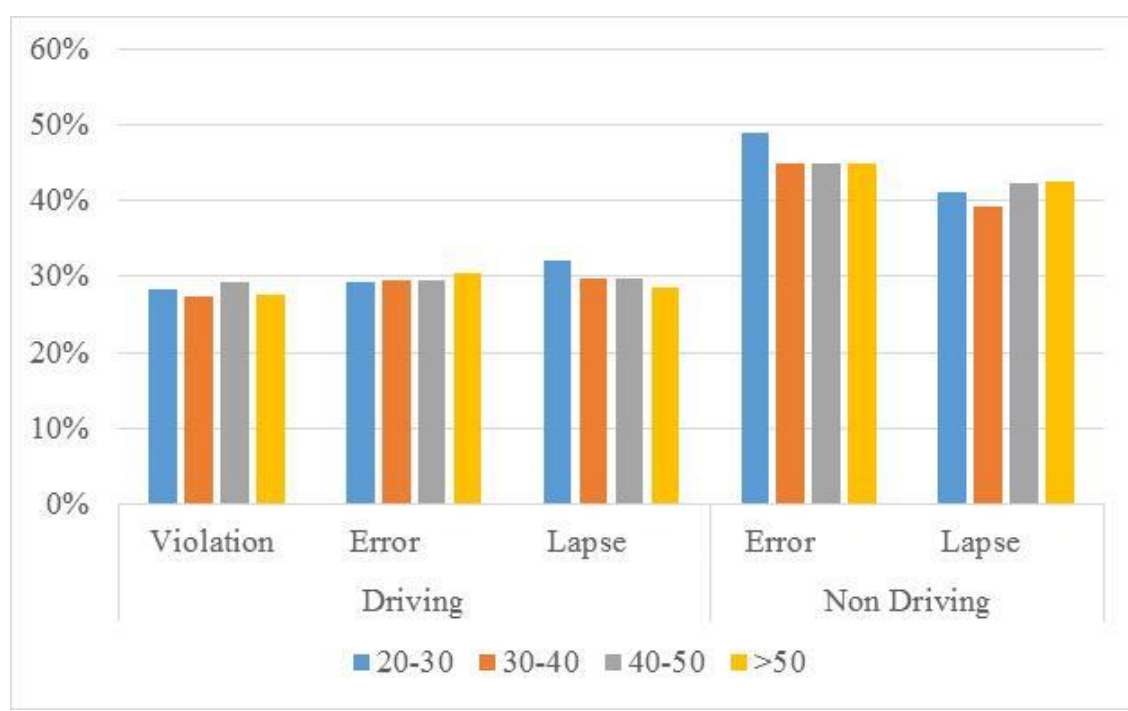

Figure 1: Behavioural variation based on driver's age 


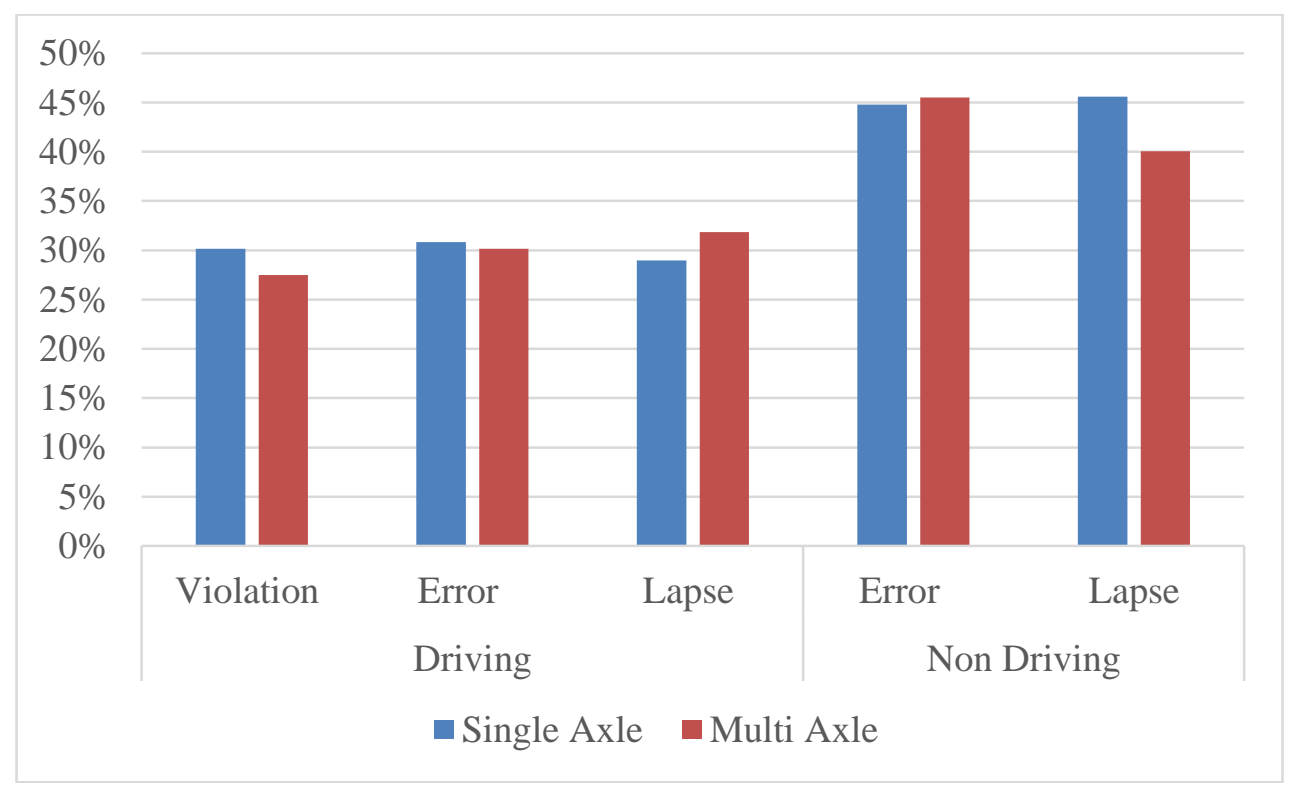

Figure 2: Behavioural variation based on vehicle type

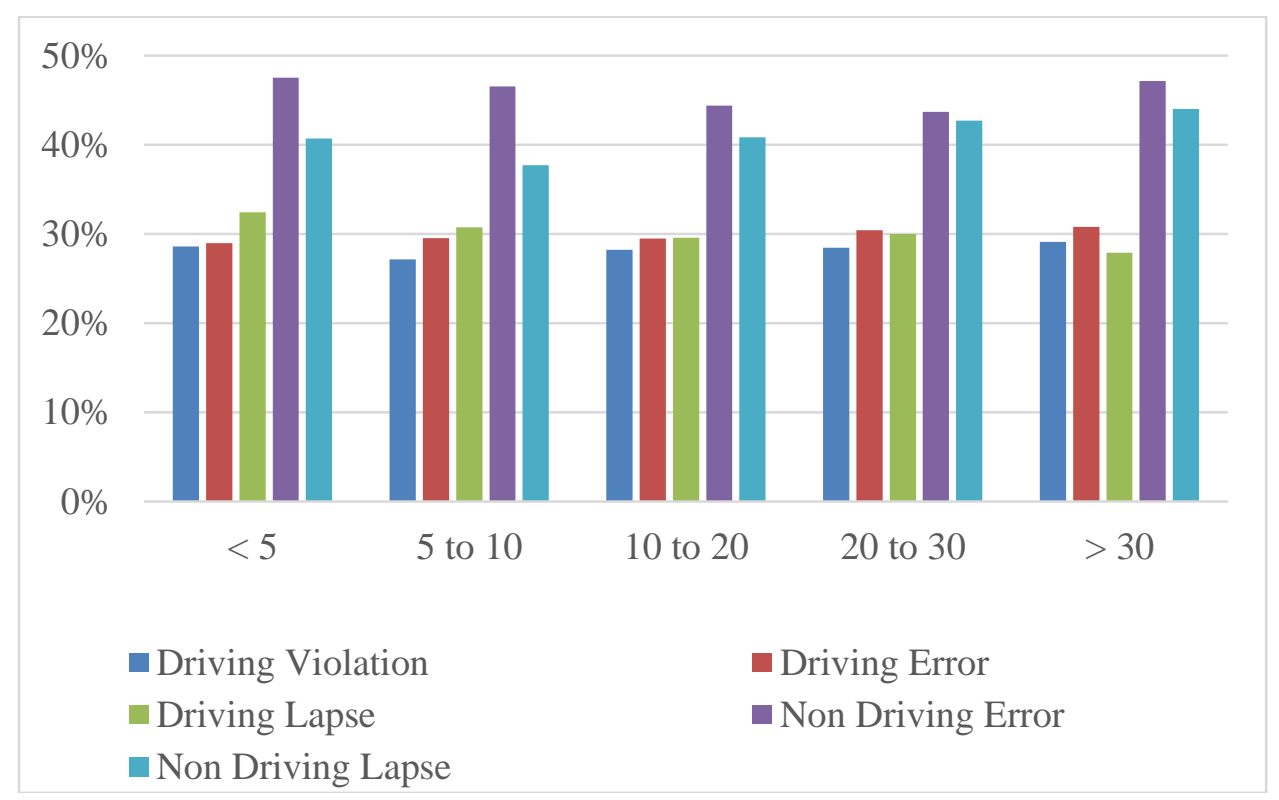

Figure 3: Behavioural variation based on driving experience 


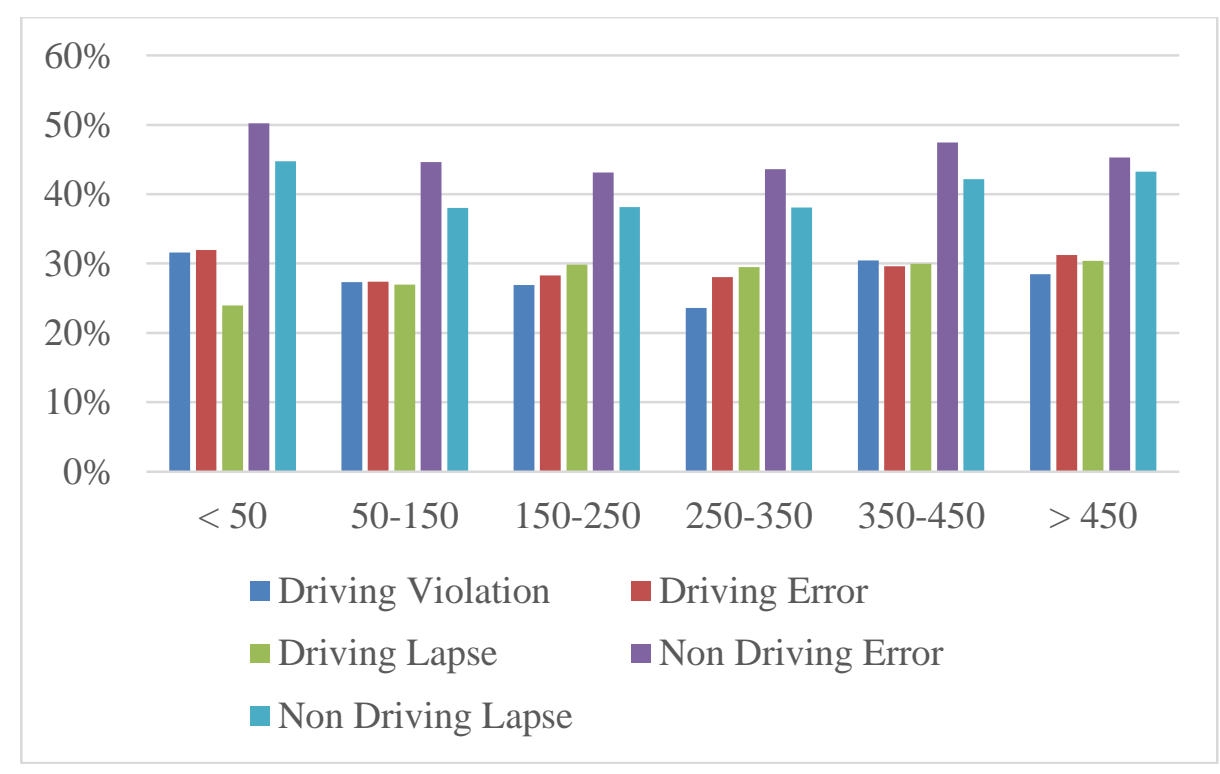

Figure 4: Behavioural variation based on kilometers per day

From the aforesaid detailed analysis of the questionnaire it can be seen that different socio -demographic characteristics of a driver have great impacts on driving behavior ie. a person with a particular set of socio demographic characteristics is more prone to commit errors than violations. Driving lapses and non-driving errors were highest for drivers in the age group between 20-30 years. Non-driving lapses were least for drivers in the age group between 30-40 years. Violations were higher in case of Single Axle trucks. Driving lapses were higher for Multi Axle trucks whereas non-driving lapses were higher in Multi Axle trucks.

\section{Conclusion}

This work dealt with the study of varying behavioural aspects of goods drivers in Kerala. Some of these aspects of driving behaviour can influence the occurrence of road accidents. The drivers of both single and multi-axle goods carriers registered in Kerala are included in this study. Inline with the analysis, it could be noticed that the driving behaviourism displayed by the goods drivers are matured through years of driving experience and is raised to be highly correlated with the demographic and socio-economic environment of the driver. Experience of the goods driver, kilometers driven per day and vehicle tonnage were found to be the most influencing factors that causes an accident. The database created was completely on drivers' personal opinion of their driving behaviourism. However, a lot of studies have determined that self-reports of driving correlate well to actual driving behaviourism. There is also a possibility of change their answers deliberately by some of the participant drivers about erroneous or intrusive driving to give a socially acceptable answer. The present study findings will be helpful to understand the behaviourism of the goods vehicles drivers in Kerala where it can be used to disseminate knowledge to user agencies and formulate implementable action plan for the reduction of road accidents due to goods vehicle.

\section{References}

Idris, F., Ismail, R. and Halim, F., W., (2015), The Model of Personality and Driver Behavior as Mediator on Road Accident Involvement among Bus Driver in Riau Province Indonesia, International Journal of Psychology and Behavioral Sciences, 5(4), 148-153.

Wang, Y., Li, L., Feng, L., Peng, H., (2014) Professional drivers' views on risky driving behaviors and accident liability: a questionnaire survey in Xining, Transportation Letters: The International Journal of Transportation Research, Vol 6, 126-135.

Bener, A., Ozkan, T., and Lajunen, T. (2008), The Driver Behaviour Questionnaire in Arab Gulf countries:Qatar and United Arab Emirates, Accident analysis and prevention, 40 (2008), 1411-1417.

Wishart, D., Freeman, J., \& Davey, J. (2006), Utilising the Driver Behaviour Questionnaire in an Organisational Fleet Setting: Are Modifications Required, Journal of the Australasian College of Road Safety 17(2), 31-38.

Musselwhite, C., (2006), Attitudes towards vehicle driving behaviour: Categorizing and contextualizing risk, Accident Analysis and Prevention, Vol 38, 324-334. 